\title{
304
}

\section{XXXVII.-On the Behaviour of Metallic Solutions with Filter Paper, and on the Detection of Cadmium.}

\section{By Thomas Bayley, Assoc. R.C.Sc.I.}

Somy time ago, while holding a wet patch, formed by dropping a solution of silver nitrate upon filter paper, in a stream of hydrogen mixed with arseniuretted hydrogen, I noticed that the metal was contained in the centre of the blot, and that the edges for about half a centimeter inwards were entirely free from metal. After being exposed to the gas, the blot presented the appearance of a black spot surrounded by a broad ring of water. I therefore made a few experiments, in order to determine whether filter paper has any power of withdrawing silver salts from solution. 7.8703 grams of silver nitrate having been dissolved in water, and diluted to 500 c.c., a quantity of this solution was placed in a beaker, and a roll of filter-paper, sufficient to absorb nearly the whole, plunged into it. After some minutes the filter-paper was removed, and as much of the liquid as possible squeezed into the beaker. It is clear that the effect of this treatment, unless the paper possesses a power of retaining the salt, would merely be to slightly concentrate the solution by evaporation.

Four experiments were made in this manner, fresh rolls of paper and fresh portions of the standard solution being used in each instance. 25 c.c. of the solution, after treatment with the paper, were mixed with hydrochloric acid, and the precipitated silver chloride dried, ignited, and weighed.

The results were as follows :-

$\begin{array}{clc}\text { Solution uned. } & \text { Ag. found. } & \text { Ag. originally present. } \\ 25 \text { c.c. } & .2182 \text { grm. } & \cdot 2500 \text { grm. } \\ 25 \text { c.c. } & .2306 " & .2500 " \\ 25 \text { c.c. } & .2353 " & \cdot 2500 " \\ 50 \text { c.c. } & .4760 " & .5000 "\end{array}$

This shows that after a roll of paper has been soaked for a few minutes in a solution of silver nitrate, the quantity of silver has materially diminished. A few experiments made by my friend, Mr. Weston, show that the same is true in the case of mercury salts. Drops of other metallic solutions were placed upon filter-paper, and submitted to the action of sulphuretted hydrogen. I found that in some cases the metal extends to the edge of the spot, and even seems concentrated there, while in others a water-ring surrounds the patch of sulphide. 
Further inquiry demonstrated that solutions of the same metal present the first or second of these phenomena, according as they are concentrated or dilute. Taking a strong solution of copper sulphate and diluting portions of it, I found that at one degree of solution the metal spreads outwards just as far as the water, and that with solutions more dilute than this, the water is separated from the metal, which remains in the centre. The more dilate the solution, the broader is the external water-ring. The exact strength of solution to give the former appearance varies with the temperature, and with the kind of paper used; the metal in a warm solution is more mobile than if the solution were cold.

The blot formed by a drop is larger on the whole, but the mobility of the metal is increased in a greater proportion than that of the water. A close Swedish paper is more efficacions in separating the salt than a loose-textured piece of common filter-paper.

A great difference is found to exist among the salts of various metals; the salts of silver, lead, and the persalts of mercury, when moderately concentrated, give a wide water-ring, while the salts of copper, nickel, and cobalt must be much more dilute to present the same appearance. Cadmium seems especially able to pass through filter-paper.

A solution of copper sulphate containing 001 gram of copper per c.c. was found to give a water-ring; at the same temperature and with the same piece of Swedish paper, a solution of cadmium sulphate of less than half that strength, gave a blat, in which the cadmium extended perfectly to the edge. Metals appear to act in this respect as though other metals were absent; this property of cadmium, therefore, affords an elegant means of detecting it in the presence of metals, the sulphides of which are black.

The considerably dilute solution is dropped upon filter-paper, and the blot allowed to extend as far as possible (this should be done in all cases) and the sulphuretted hydrogen then turned on. The black patch is found to be surrounded by a vivid yellow ring of cadmium sulphide. A solution rich in nickel, cobalt, or iron may in like manner be examined for these metals, in presence of smaller quantities of copper, lead, mercury, and silver.

The blot having spread, is exposed to sulphuretted hydrogen, and afterwards held over a bottle of ammonium sulphide, when the waterring becomes black. This method, however, is extremely suited to the detection of cadmium. It was found that the presence of free acid much increases the mobility of copper, so that before testing for cadmium in this manner, the solution, if acid, should be made slightly alkaline by ammonia.

Similar experiments with the hydrates of calcium, sodium, and vOL. IXXIII. 
ammonium dropped upon turmeric paper, showed that the water-ring is formed if the solutions are dilute.

When they are concentrated the alkali extends to the edge of the blot, and indeed seems concentrated there, for the brown patch is surrounded by a ring darker in colour than the other parts.

These properties of metallic solutions are probably closely connected with capillarity.

This investigation was conducted in the Chemical Laboratory of the Royal College of Science, Dublin. 